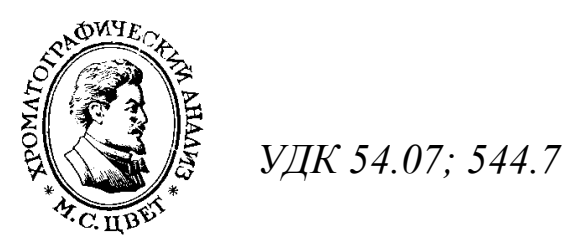

\title{
Использование хлорида серебра для масс- спектрометрического исследования аминокислот на углеродных сорбентах
}

\author{
Кузнецова Е.С., Пыцкий И.С., Буряк А.К. \\ Федеральное Государственное Бюджетное Учреждение Науки Институт физической химии и \\ электрохимии имени А.Н. Фрумкина РАН, Москва
}

Поступила в редакцию 31.01.2017 г.

\begin{abstract}
Проведено исследование сорбированных на различных сажах модельных соединений (пяти аминокислот) для оценки возможности их определения. Показано, что добавление к исследуемым сажам хлорида серебра позволяет повысить информативность и чувствительность определения исследуемых соединений.
\end{abstract}

Ключевые слова: масс-спектрометрия, хлорид серебра, кластерообразование, предел чувствительности, углеродные сорбенты

\section{Silver chloride using for mass-spectrometric investigation of amino acids on carbon sorbents}

\author{
Kuznetsova E.S., Pytskii I.S., Buryak A.K. \\ Institute of Physical chemistry and Electrochemistry, RAS, Moscow
}

\begin{abstract}
Different types of carbon blacks and five amino acids was investigated Mass spectrometry method with laser desorption / ionization was used. The method allows us to investigate not only the ionization from any surface, but also in the ionisation mass spectra judge the state of the surface under study. The use of this method for the study of surfaces of various types of carbon blacks not only to evaluate the sorption characteristics of carbon blacks, but also the state of the surface after sorption.We studied all the amino acids on the stainless steel surfaces, different soot and on the same soot with the addition of silver chloride. It was shown that ionization on soots more efficiently than on the stainless steel surface. The addition of silver chloride to the test compound produces peaks dimer of amino acids and adducts of silver. The method allows to increase the sensitivity and accuracy Method is «green chemistry» method and requires no toxic chemicals.
\end{abstract} bents.

Keywords: mass-spectrometry, silver chloride, formation of clusters, detection limit, carbon sor-

\section{Введение}

Наиболее часто в качестве сорбентов используются углеродные материалы различной природы [1-2]. Такие углеродные материалы как графитированные и термические сажи благодаря своей инертной поверхности могут быть использованы для выделения органических соединений из водных растворов. Особенное преимущество использования таких сорбентов - возможность выделения лабильных соединений без использования хемосорбции. Для оценки возможности использования таких сорбентов проведено исследование сорбции модельных соединений на поверхностях 
углеродных материалов. Для надёжного определения сорбированных соединений применяли метод масс-спектрометрии с поверхностно-активированной лазерной десорбцией/ионизацией. Показано, что масс-спектрометрия также способна эффективно определять сорбируемые вещества при нанесении на поверхность сорбента веществ-матриц.

\section{Эксперимент}

В качестве сорбентов использовали различные типы саж: Графитированная термическая сажа Carbopack (12 м²/г), графитированная печная сажа ПМ-16Э, $\left(16 \mathrm{~m}^{2} / \Gamma\right)$, печная сажа ПМ-75 $\left(75 \mathrm{~m}^{2} / \Gamma\right)$ и Печная сажа Vulcan XC 72R (265 м²/г). Для масс-спектрометрического исследования использовали масс-спектрометр Bruker Ultraflex (Bruker, Германия), оборудованные азотным лазером ( $\lambda=337$ нм). Частота импульсов варьировалась от 5 до 20 Гц, количество выстрелов - от 10 до 100, мощность одного импульса - от 5 до 100\%. В качестве модельных объектов исследования использовали набор аминокислот: треонин, фенилаланин, аспарагин, гистидин и пролин (Sigma Aldrich, США). В предыдущих работах авторов было показано значительное увеличение эффективности ионизации этих и других аминокислот при нанесении их на различные углеродные сорбенты [3-4], что согласуется с мировыми результатами [5-7].

Для увеличения эффективности ионизации и информативности масс-спектров использовали галогениды серебра, синтезированные в водных растворах смешением растворов нитрата серебра и соответствующего галогенида калия (Реахим, Россия). [8-9]. Аминокислоты наносили на поверхность нержавеющей стали (холостой опыт) и углеродного сорбента из водно-ацетонитрильного раствора (1:1 по объёму). Вода milli-Q, ацетонитрил JT Baker, США). В раствор галогенидов серебра перед нанесением на поверхность добавляли ацетонитрил в эквивалентном водному раствору количестве. Сначала наносили раствор аминокислоты, сушили на воздухе в течение 10 минут, затем наностили раствор галогенида серебра. Концентрации подбирались исходя из конкретной аминокислоты и указаны в таблице 1.

Таблица 1. Концентрации растворов аминокислот и хлорида серебра, нанесённые на поверхность сорбента

\begin{tabular}{|c|c|c|c|}
\hline \multirow{2}{*}{ Аминокислота } & \multicolumn{3}{|c|}{$\begin{array}{r}\left.\text { Концентрация суспензии хлорида серебра (мкг/дм }{ }^{3}\right) \text { в трёх } \\
\text { различных растворах аминокислот }\end{array}$} \\
\cline { 2 - 4 } & $\begin{array}{c}\text { Раствор 1 } \\
(10 \text { мкг/дм }\end{array}$ & $\begin{array}{c}\text { Раствор } 2 \\
(100 \text { мкг/дм }\end{array}$ & $\begin{array}{c}\text { Раствор 3 } \\
\left(1000 \text { мкг/дм }{ }^{3}\right)\end{array}$ \\
\hline Аспарагин & $10^{-11}$ & $10^{-11}$ & $10^{-11}$ \\
\hline Гистидин & $10^{-12}$ & $5 \cdot 10^{-11}$ & $10^{-11}$ \\
\hline Пролин & $10^{-11}$ & $10^{-11}$ & $10^{-11}$ \\
\hline Треонин & $5 \cdot 10^{-12}$ & $5 \cdot 10^{-11}$ & $10^{-11}$ \\
\hline Фенилаланин & $10^{-16}$ & $10^{-16}$ & $10^{-15}$ \\
\hline
\end{tabular}

\section{Обсуждение результатов}

Известно, что при масс-спектрометрическом исследовании методом МАЛДИ основной проблемой является получение воспроизводимых и информативных массспектров. Это особенно важно при исследовании высокоразвитых поверхностей, которые могут как увеличивать так и уменьшать эффективность ионизации, а, следова-

Кузнецеова и др. / Сорбционные и хроматографические процессы. 2017. Т. 17. № 2 
тельно, может ухудшаться предел чувствительности метода. Так на рисунке 1 показан масс-спектр гистидина, зарегистрированный со стандартной поверхности с содержанием аналита 100 мкг/дм³ ${ }^{3}$. Из масс-спектра видно, что даже при такой большой концентрации соотношение сигнал/шум самого большого пика с m/z=194 Да не превышает 6-7. Следовательно, предел чувствительности не может быть меньше этого значения.

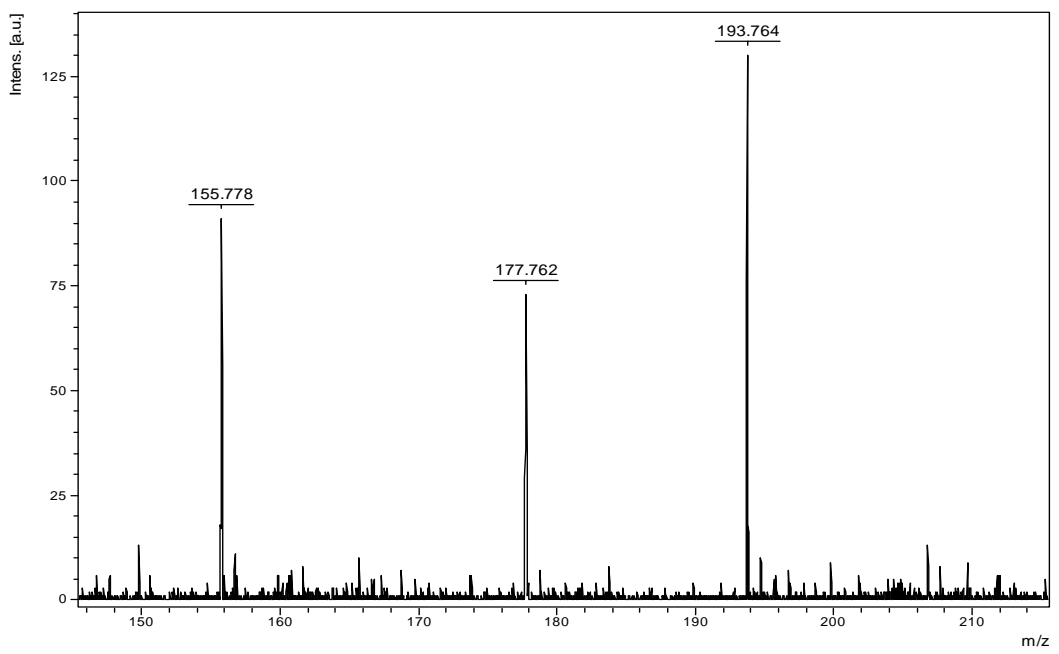

Рис. 1. Фрагмент масс-спектра гистидина, полученный в режиме регистрации положительных ионов на поверхности нержавеющей стали в количестве 5 нг/мм².

155.8 - гистидин +Н+, 177.8 - гистидин+Na+, 193,8 - гистидин+К+

Для увеличения чувствительности совместно с анализируемым образцом на поверхности саж добавляли суспензии галогенидов серебра. Из литературы известно, что соли серебра часто используются в качестве катионизирующего агента для перевода в ионизированное состояние малолетучих или плохо ионизирующихся соединений [10]. Сделано предположение, что использование кластерообразующих соединений серебра (например, хлорида серебра) может не только повысить эффективность ионизации, но и инициировать кластерообразование в молекулах аналита.

Из масс-спектра на рисунке 2 и таблицы 2 видно, что даже при количестве аминокислоты на поверхности в количестве 100 пг/мм² чётко регистрируются пики аддуктов с калием и натрием. Кроме этого, при использовании кластерообразующей добавки генерируется высокоинтенсивный пик димера фенилаланина, который невозможно получить не при каких иных условиях. Также получены два изотопных пика на массах 271 и 273 Да, соответствующие иону аддукта фенилаланина с серебром.

Таблица 2. Отнесение пиков масс-спектра на рисунке 2.

\begin{tabular}{|c|c|c|}
\hline № & $\mathrm{m} / \mathrm{z}$, Да & Ион \\
\hline 1 & 188 & Фенилаланин $+\mathrm{Na}^{+}$ \\
\hline 2 & 204 & Фенилаланин $+\mathrm{K}^{+}$ \\
\hline 3 & $271 ; 273$ & Фенилаланин $+\mathrm{Ag}^{+}$ \\
\hline 4 & 369 & Димер фенилаланина $+\mathrm{K}^{+}$ \\
\hline
\end{tabular}

Следует отметить, что идентификация соединений по аддукту с ионом серебра удобна по нескольким причинам. Во-первых, аддукт с серебром состоит из двух изотопных пиков, а не из одного, что позволяет повысить надёжность идентификации соединений, сорбированных на сажах. Кроме того, благодаря высокой ионизирующей способности, аддукты серебра имеют значительно большую эффективность 
ионизации, что позволяет определять исследуемые соединения на сажах с большей чувствительностью и при количествах, которые невозможно обнаружить по пикам стандартных аддуктов аминокислот.

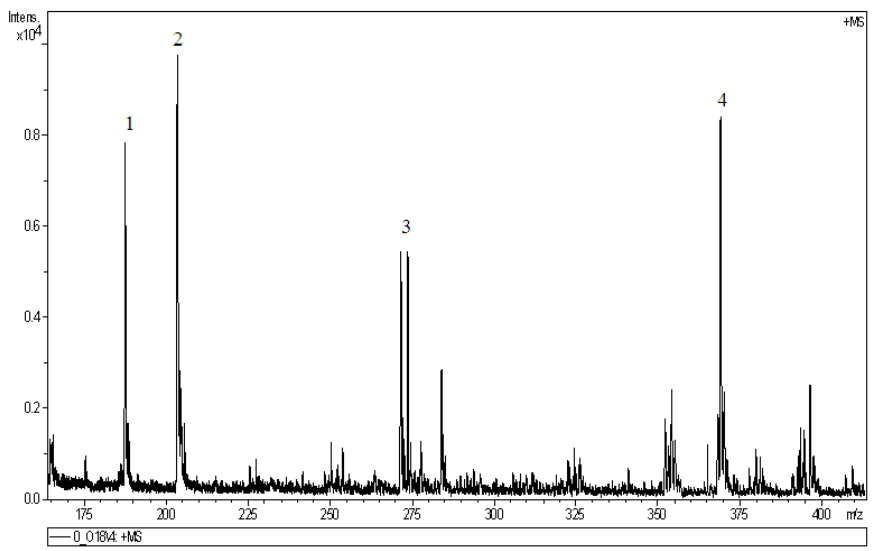

Рис. 2. Фрагмент масс-спектра фенилаланина, полученный в режиме регистрации положительных ионов на поверхности печной сажи ПМ-75 с добавкой хлори-

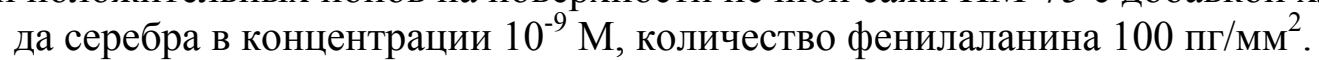

\section{Заключение}

Из таблицы 3 следует, что применение кластерообразующей добавки хлорида серебра к саже с нанесёнными модельными соединениями позволяет снизить пределы чувствительности почти на порядок по всем исследованным аминокислотам.

Таблица 3. Сравнение пределов чувствительности аминокислот, адсорбированных на различных сажах при определении с добавлением хлорида серебра и без добавления его.

\begin{tabular}{|c|c|c|}
\hline \multirow{2}{*}{ Аминокислота } & \multicolumn{2}{|c|}{$\begin{array}{c}\text { Предел чувствительности по модельным соединениям, } \\
\text { адсорбированным на различных сажах, нг/мм }\end{array}$} \\
\cline { 2 - 3 } & $\begin{array}{c}\text { Без добавления хлорида } \\
\text { серебра }\end{array}$ & С добавлением хлорида серебра \\
\hline Аспарагин & 7 & 0.8 \\
\hline Гистидин & 5 & 0.6 \\
\hline Пролин & 10 & 0.4 \\
\hline Треонин & 5 & 0.1 \\
\hline Фенилаланин & 2 & \multicolumn{2}{|c|}{} \\
\hline
\end{tabular}

Таким образом, метод МАЛДИ является альтернативой классическим методам анализа таких соединений на сажах. Метод позволяет проводить анализ с минимальной и простой в исполнении пробоподготовкой. Метод относится к области «зелёной химии»: используется только вода в качестве растворителя.

\section{Список литературы}

1. Wang H., Ma H. Zheng W., An D., Na C.// 2. Ye T., Durkin D. P., Hu M., Wang X. et al. ACS Appl. Mater. Interfaces. 2014. Vol. // ACS Appl. Mater. Interfaces. 2016. Vol. 6 (12). зp. 94269434.

8 (28). pp. 17739-17744. 
3. Кузнецова Е.С., Буряк А.К. // Физикохимия поверхности и защита материалов. 2011. T. 47. № 6. C. 586-593.

4. Кузнецова Е.С., Ульянов А.В., Буряк А.К. // Журнал физической химии. 2009. Т. 83. № 4. C. 638-642.

5. Min Q., Zhang X., Chen X., Li S. et al. // Anal. Chem, 2014. Vol. 86 (18). pp. 9122-9130.

6. Qin H., Zhao L., Li R., Wu R., Zou H. // Anal. Chem. 2011. Vol. 83 (20). , pp. 77217728.

\section{References}

1. Wang H., Ma H. Zheng W., An D., Na C., ACS Appl. Mater. Interfaces, 2014, Vol. 6 (12), pp. 9426-9434. DOI: $10.1021 / \mathrm{am}$ 5010656Available at: $\mathrm{www}$.pubs.acs.org

2. Ye T., Durkin D. P., Hu M., Wang X. et al., ACS Appl. Mater. Interfaces, 2016, Vol. 8 (28), PP 17739-17744 DOI: 10.1021/acsami.6b08355 Available at: www.pubs.acs.org

3. Kuznetsova E.S., Buryak A.K., Protection Metals, 2011, Vol 47, No 6, pp. 586-593.

4. Kuznetsova E.S., Uleanov A.V., Buryak A.K., J. of Phys. Chem.. 2009, Vol. 83, No 4, pp. 638-642.

5. Min Q., Zhang X., Chen X., Li S., Zhu J.J., Anal. Chem., 2014, Vol. 86 (18), pp. 91229130 DOI: 10.1039/C6RA21083J Available at: www.pubs.acs.org

Кузнецова Елена Сергеевна - старший научный сотрудник лаборатории синтеза и исследования сорбентов, к.х.н. Институт физической химии и электрохимии имени А.Н. Фрумкина РАН, Москва

Пыцкий Иван Сергеевич - старший научный сотрудник лаборатории физикохимических основ хроматографии и хроматомасс-спектрометрии, к.Х.н. Институт физической химии и электрохимии имени А.Н. Фрумкина РАН, Москва

Буряк Алексей Константинович - заведующий лабораторией физико-химических основ хроматографии и хромато-массспектрометрии, проф, д.х.н. Институт физической химии и электрохимии имени А.Н. Фрумкина РАН, Москва
7. Ugarov M.V., Egan T., Khabashesku D.V., Schultz J.A. et al. // Anal. Chem. 2004. Vol. 76 (22). pp. 6734-6742.

8.Пыцкий И.С., Буряк А.К., Сухоруков Д.О. // Сорбиионные и хроматографические проиессы. 2009. Т. 9. № 6. С. 789-795.

9.Пыцкий И.С., Ревельский И.А., Буряк А.К. // Масс-спектрометрия. 2010. Т. 7. № 1. C. $35-40$.

10. Pastor S.J., Wilkins C.L. // J. of Amer. Soc. for Mass Spec. 1997. Vol. 8. pp. 225-233.

6. Qin H., Zhao L., Li R., Wu R., Zou H., Anal. Chem., 2011, Vol. 83 (20), pp. 77217728. DOI: 10.1021/jp035246f Available at: www.pubs.acs.org

7. Ugarov M.V., Egan T., Khabashesku D.V., Schultz J.A. et al., Anal. Chem., 2004, Vol. 76 (22), pp. 6734-6742 DOI:10.1021/ac049192x Available at: www.pubs.acs.org

8. Pytskii I.S., Buryak A.K., Sukhorukov D.O., Sorbtsionnye $i$ khromatograficheskie protsessy, 2009, Vol. 9, No 6, pp. 789-795.

9. Pytskii I.S., Revelsky I.A., Buryak A.K., Mass-spectrometria, 2010, Vol. 7, No 1, pp. 3540.

10. Pastor S.J., Wilkins C.L., J. of Amer. Soc. for Mass Spec., 1997, Vol. 8, pp. 225-233. DOI: 10.1016/S1044-0305(96)00257-7 Available at: www.pubs.acs.org

Kuznetsova Elena S. - PhD (chemistry), laboratory of synthesis and investigation of sorbents, Institute of Physical chemistry and electrochemistry, Moscow.

Pytskii Ivan S. - PhD (chemistry), laboratory of physical-chemical basics of chromatography and chromato-mass-spectrometry, Institute of Physical chemistry and electrochemistry, Moscow. E-mail: ivanpic4586@gmail.com

Buryak Alexey K. - prof., grand $\mathrm{PhD}$ (chemistry), laboratory of physical-chemical basics of chromatography and chromato-mass-spectrometry Institute of Physical chemistry and electrochemistry, Moscow. 